\title{
Students Perception to Aero Intel Mobile Application in Learning Aircraft Airframe
}

\author{
Norisza Dalila Ismail \\ Aircraft Maintenance Department, Politeknik Banting Selangor, Persiaran Ilmu, Jalan Sultan Abdul \\ Samad, 42700 Banting, Selangor, Malaysia.
}

\begin{abstract}
Aero Intel mobile application (mobile app) is an interactive learning application which is specific to aircraft airframe providing information to help aircraft maintenance engineering students. The objective for this study is to investigate students' perceptions towards Aero Intel mobile app. Quantitative study using questionnaires have involved 78 respondents of semester 1 students of Diploma Engineering of Aircraft Maintenance from Politeknik Banting Selangor. The questionnaires constructed about ownership of smartphone, frequency use of type of apps, are they interested to download educational app and most importantly, students' perceptions after exploring the Aero Intel mobile app. All respondents owned smartphones and 97.4\% interested to use apps for academic purposes. The data obtained were analyzed using Statistical Package for Social Science (SPSS). The finding results revealed the students have positive perception towards Aero Intel mobile application. Thus, the use of this application is expected to help students' understanding in aircraft airframe and various feedbacks given to encourage educator as the developer to explore and improving development of mobile app for diverse needs in teaching and learning.
\end{abstract}

\section{Key words: Aero Intel, Mobile Apps, Aircraft airframe, Students' perception}

\section{INTRODUCTION}

A smartphone is a handheld size technology device equipped with operating system (OS) which not only use as mobile telephone [1]. It enables the user to access web 2.0 same as accessing the internet in normal computer [2]. It also acts as a platform for user to install and run applications and for developers to develop and upload the application. The use of technology for educational learning improves conventional teaching method and emphasizes blended learning [3]. The sophistication of the world information and communication technology has a positive impact in the educational system of the world, especially countries that are developing. Students' ability in daily usage in the use of mobile apps both inside and outside classroom will not limit their knowledge for educational purposes [4].

Development of mobile technology leverages a greater opportunity in changing ways of student to gain information and learning method [5]. This to create learning environment much more interesting compare to conventional method which only referring to text books.

Aero Intel mobile application (mobile app) was initiated and developed providing informative learning about airframe of an aircraft. Aircraft airframe which is mechanical structure basically involving the fuselage, wings, flight control surfaces, empennage, cowlings, landing gear without the propulsion system [6]. Aircraft airframe is one of topic need to be learned among other subject in aircraft maintenance. Figure 1 shows the airframe of a fixed-wing aircraft which consists of five principal unit.

The aim of this study is to investigate students' perception towards Aero Intel mobile app for aircraft maintenance engineering students but the selected case is Politeknik Banting Selangor.

Corresponding Author: Norisza Dalila Ismail, Department of Aircraft Maintenance, Politeknik Banting Selangor, Persiaran Ilmu, Jalan Sultan Abdul Samad, 42700 Banting, Selangor. Email: norisza@ polibanting.edu.my Phone: +60331201625 


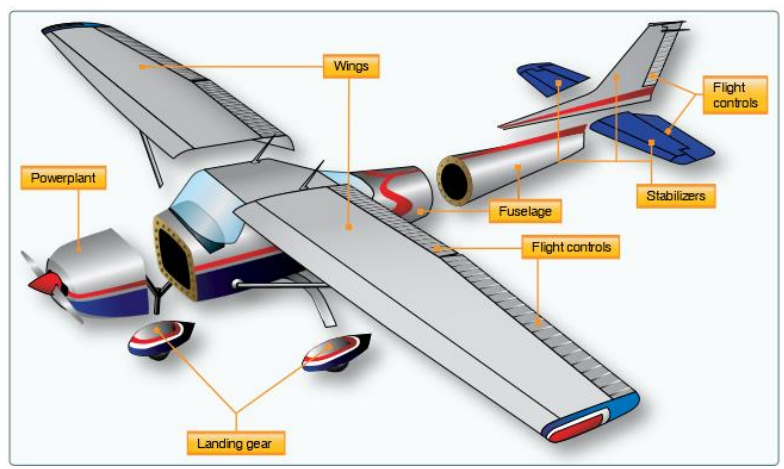

Figure 1 Principal airframe units [5]

Politeknik Banting Selangor (PBS) is the only polytechnic in Malaysia offering Diploma Engineering in Aircraft Maintenance for three-year duration. PBS is governed and administered in accordance with Department of Polytechnic and Community College Education, Ministry of Education Malaysia.

\section{AERO INTEL MOBILE APP}

Aero Intel mobile app is very useful in improving the knowledge about aircraft airframe. Furthermore, Aero Intel application enable user to bring that information everywhere and also easier to access without internet connection. This application also consists of quizzes to test user's knowledge. The app is constructed into nine aircraft zones which is known as zone 100 is about lower fuselage, zone 200 is about upper fuselage, zone 300 is stabilizer or empennage, zone 400 is about power plant, zone 500 is about left wing, zone 600 is about right wing, zone 700 is about landing gears, zone 800 is about doors and zone 900 is about lavatories. Aircraft zoning is specified by the Air Transport Association of America which is now known as Airlines for America, in the ATA-100 Specification [7]. Aircraft zones are designated physical areas of an aircraft that identify where maintenance activities occur. Figure 2 shows the starting screen of Aero Intel mobile app. User need to choose the take-off button to proceed and depart button to exit. List of aircraft zones, videos link and quiz will appear from the menu button as shown in Figure 3. Figure 4 is the explanation about empennage of an aircraft in zone 300 .

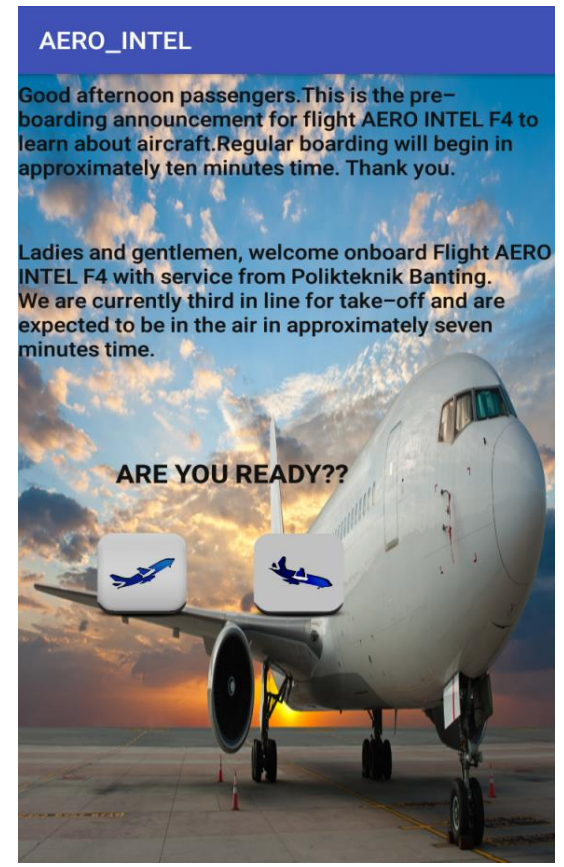

Figure 2 Starting screen of Aero Intel app

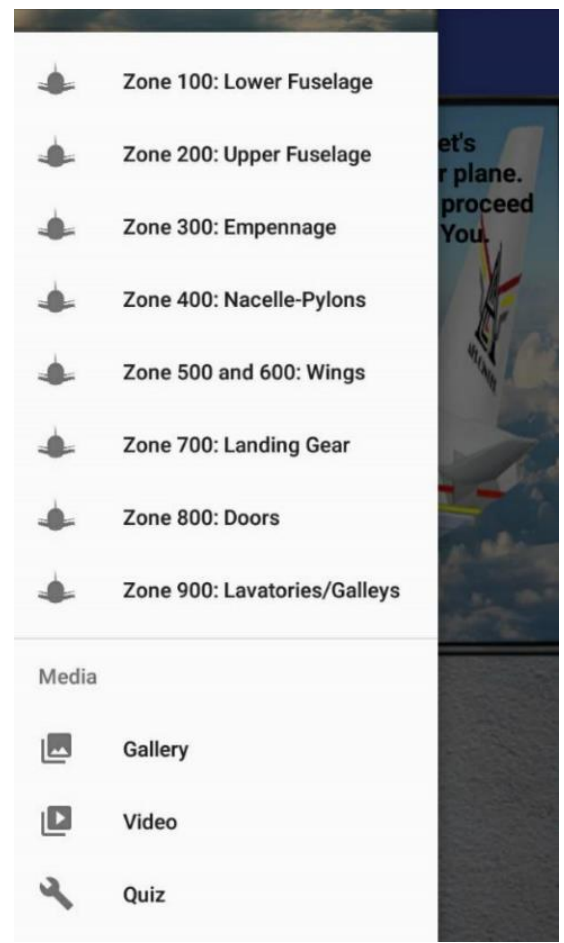

Figure 3 Aircraft zone information from menu button

The content covered in Aero Intel mobile app including aircraft airframe with general information about each zone with no specific aircraft type. Accordingly, this Aero Intel application only can be download or install in Android version 2.3 and above as the coding is not support by the iOS for Apple smartphone. This app does not require internet data 
after the installation except for the videos thus it will help user to get through the apps more efficiently without for a long time to load for information needed. It featured quizzes to build user understanding after learning and gaining information in the apps.

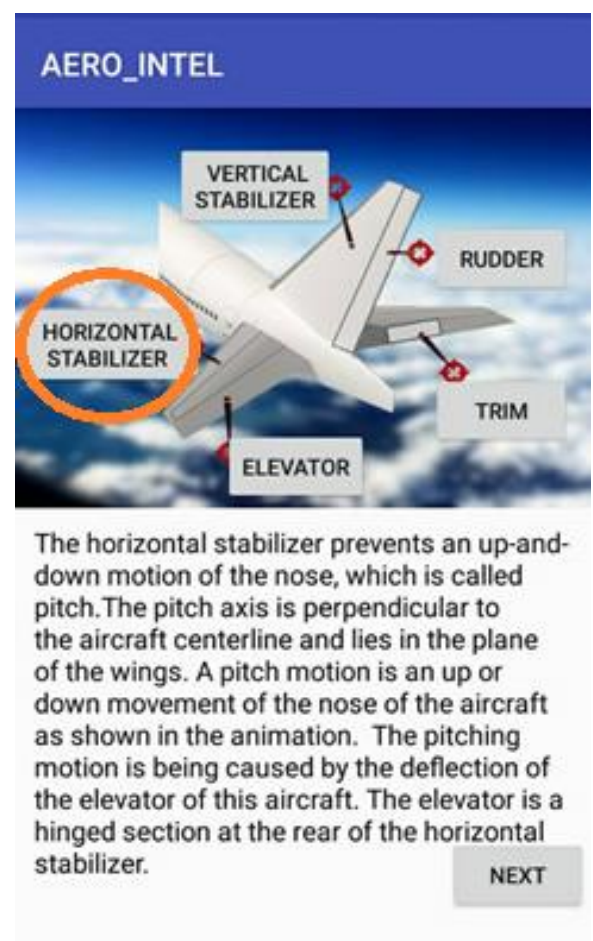

Figure 4 Explanation of Zone 300 Empennage

\section{METHODOLOGY}

The descriptive method of research was used in this study with the questionnaire checklist as the main tool. The questionnaire was constructed and distributed to the respondents. A total of 78 sets of questionnaires were distributed to all semester one students studying Diploma Engineering in Aircraft Maintenance in Politeknik Banting Selangor. Prior answering the questionnaires, students were introduced to mobile apps Aero Intel and explored the application in their android smart phone. The data collected on September 2017.

The significant of Aero Intel mobile app with semester one students is that the course DWM1222 Aviation Introductory has aircraft airframe topic covered as in the syllabus requirement. The data then were gathered, analyzed and interpreted using appropriate statistical measures such as frequencies, percentages and means. The questionnaire consisted combination of 18 items with mix close ended and likert scale question and distributed into three sections,
Section A (3 items), Section B (6 items) and Section C (10 items).

Section A consists of the demographic characteristics of the respondents such as gender, age and class.

Section B focused on the type of smartphone brand owned and frequent usage for mobile app categories which has been rated by the respondent based on likert scale question as in Table 1. As the main aim of this questionnaire was to enhance our understanding how students use their smartphones. Table 3 contains 11 categories of mobile applications to explore students' frequent usage for each category. Five likert scale as in Table 1 were used to determine frequent usage of mobile apps in each category.

Section $\mathrm{C}$ based on close ended Yes and No represents the item to determine the level of readiness and respondents' perception towards Aero Intel mobile app. There are 9 questions from question 10 until 18 in Section C to explore students' experience with Aero Intel mobile app. Respondents required to answer Yes or No for question 10 until 18.

Table 1. Frequent usage likert scale for each category

\begin{tabular}{ll}
\hline Very frequently & more than 2 times a day \\
\hline Frequently & $1-2$ times a day \\
\hline Occasionally & $1-2$ times a week \\
\hline Rarely & $2-3$ times a month \\
\hline Very Rarely & once a month or less \\
\hline Do not use & Never use \\
\hline
\end{tabular}

\section{RESULTS}

\section{Demographic Profiles of Respondents}

Overall of $98.7 \%$ of the respondents were 18 years old while $1.3 \%$ was 20 years old. There are 57 $(73.1 \%)$ male respondents and 21 (26.9\%) female respondents involved in this study as shown in Table 2.

Table 2. Demographic Profile of Respondents

\begin{tabular}{ccc}
\hline Age & $\mathbf{1 8}$ & $\mathbf{2 0}$ \\
& $\mathbf{7 7}(\mathbf{9 8 . 7 \%})$ & $\mathbf{1 ( 1 . 3 \% )}$ \\
\hline Gender & Male & Female \\
& $57(73.1 \%)$ & $21(26.9 \%)$
\end{tabular}




\section{Smartphone Usage}

Respondents were asked the brand of smartphone they are currently used. 23 (29.5\%) respondents use Samsung brand while 15 (19.2\%) using Apple smartphone. The other brand such as Oppo is owned by $10.3 \%$ of the respondents. The distribution of smartphone ownership based on brand is shown in Figure 2 .

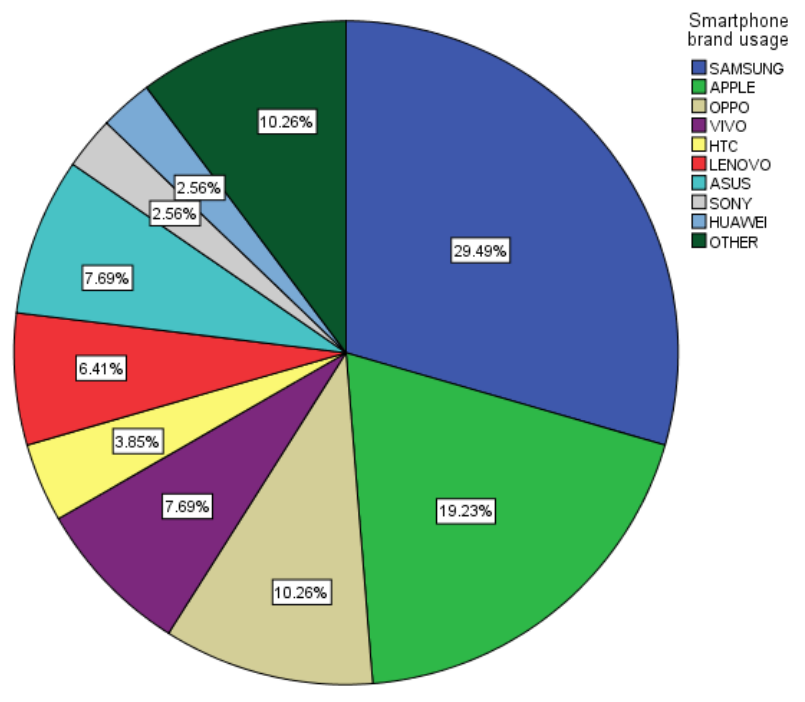

Figure 5 Smartphone brand owned

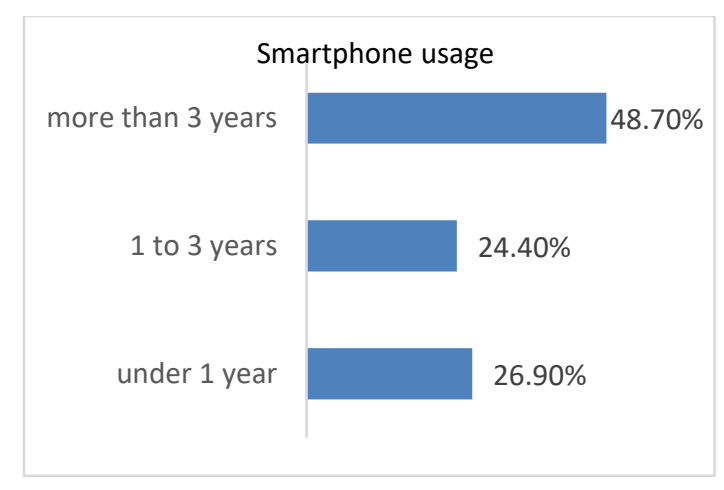

Figure 6 Smartphone usage

As shown in Figure 6, 48.70\% respondents have use smartphone more than 3 years. $26.90 \%$ respondents have use the smartphone below one year while $24.40 \%$ respondents use their smartphone between 1 to 3 years.

The study found that all respondents were familiar with internet accessibility. Questions 6-7 asked the respondents if they use the internet using their smartphone. As shown in Figure 7, 79.5\% of the respondents use both mobile data and wifi to access the internet using their smartphone. $11.5 \%$ of the respondents were using paid mobile data while $9 \%$ using wifi service to access the internet. Question 8 asked respondents if they interested in downloading apps for academic purposes. The result indicated majority of respondents $97.4 \%$ interested in downloading apps for academic purposes as shown in Figure 8.

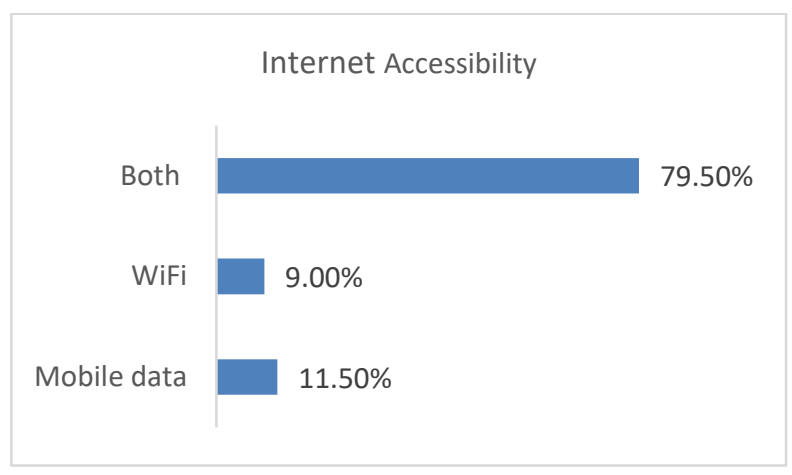

Figure 7 Internet accessibility

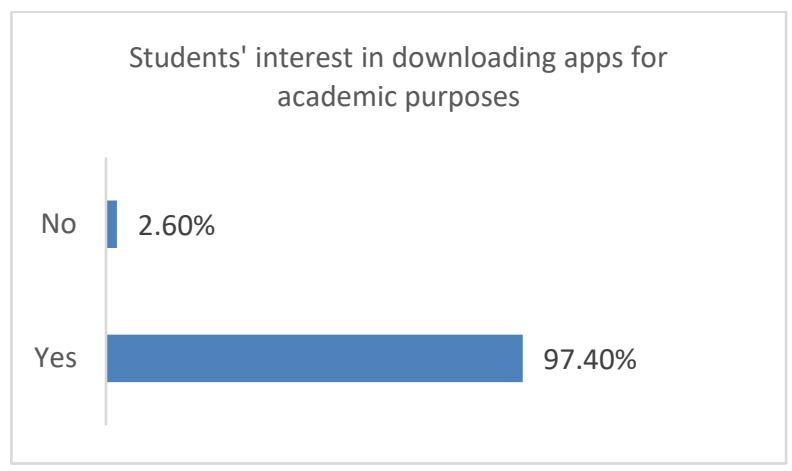

Figure 8 Students' interest in downloading apps for academic purposes.

As shown in Table 3 the results indicate that the highest categories of frequent app usage are in social category (email, Twitter, Facebook, Instagram) with the mean score of 4.90. Search engine (Yahoo!, Google, Safari) category with the mean score of 4.51 while entertainment (Youtube, Astro on the go) category had a mean score of 4.29. Banking (bank account, transfer) category is the least usage among respondents with the mean score of 1.41 .

Table 3. Mean score for each category of frequent usage in mobile app

Category of app frequent used Mean Social (email, Twitter, Facebook, 4.90 Instagram)

Search engines (Yahoo!, Google, Safari)

Entertainment (Youtube, Astro on the go)

Tools and productivity (calendar, note, alarms, flashlight)

\begin{tabular}{|l|}
\hline 4.51 \\
\hline 4.29 \\
\hline 4.05 \\
\hline
\end{tabular}




\begin{tabular}{r|l|} 
Games (AngryBirds, & 3.69 \\
Travel, life (Maps) & 2.40 \\
\cline { 2 - 2 } CandyCrush,ClashofClan, MobileLegend & \\
Shopping (Lazada, Ebay, Lelong) & 2.18 \\
Hobbies (cookbooks) & 2.03 \\
\cline { 2 - 2 } Health and Fitness (MyFitnessPal, step & 2.00 \\
counter) & \\
\cline { 2 - 2 } Casual reading (ebooks, comics) & 1.95 \\
Banking (bank account, transfer) & 1.41 \\
\end{tabular}

Students' perception to the use of Aero Intel mobile app

Table 4 shows total number of respondents' response analysis from question $10-18$. Referring to Figure 9, majority of the respondents answered Yes with $94.8 \%$ compare to $5.2 \%$ respondents answered No for all questions in Section C. Table 4 shows overall analysis of respondents' answers by each question. All respondents answered Yes in question 13 and 17 which indicate that students increase their knowledge in aircraft airframe and it is beneficial for students to use Aero Intel app. 16 respondents answered the design of the app is not interactive. For question 15, Aero Intel app has met expectation for 73 respondents.

Table 4. Total number of respondents' response analysis from question $10-18$

\begin{tabular}{|l|l|l|}
\hline Question & Yes & No \\
\hline $\begin{array}{l}\text { 10. Is Aero Intel app easy for you } \\
\text { to access? }\end{array}$ & 71 & 7 \\
\hline $\begin{array}{l}\text { 11. Is the design interactive } \\
\text { 12. Is this app will save time to } \\
\text { get information regarding } \\
\text { aircraft airframe? }\end{array}$ & 77 & 16 \\
\hline $\begin{array}{l}\text { 13. Is this app increase your } \\
\text { knowledge about aircraft } \\
\text { airframe? }\end{array}$ & 78 & 0 \\
\hline $\begin{array}{l}\text { 14. Do you understand the } \\
\text { content in this app? }\end{array}$ & 76 & 2 \\
\hline $\begin{array}{l}\text { 15. Has Aero Intel app met your } \\
\text { expectation? }\end{array}$ & 73 & 5 \\
\hline $\begin{array}{l}\text { 16. Would you recommend to } \\
\text { your friends/others to have this } \\
\text { app? }\end{array}$ & 76 & 2 \\
\hline $\begin{array}{l}\text { 17. Do you think Aero Intel app } \\
\text { is beneficial for students? }\end{array}$ & 78 & 0 \\
\hline $\begin{array}{l}\text { 18. Are you interested to use this } \\
\text { app? }\end{array}$ & 75 & 3 \\
\hline \begin{tabular}{l} 
TOTAL \\
\hline
\end{tabular} & 666 & 36 \\
\hline
\end{tabular}

Whole comparison of respondents' responses

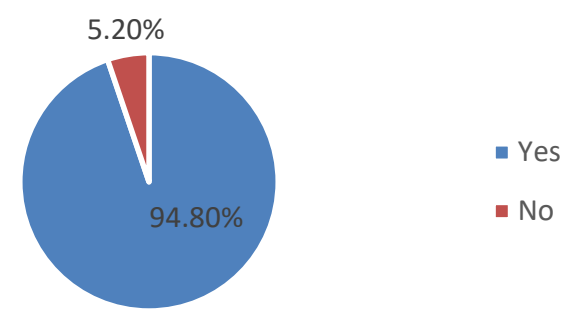

Figure 9 Whole comparison of respondents' responses from Q10-Q18.

\section{CONCLUSION}

This chapter concludes by summarising the key findings of the questionnaire. Firstly, the main characteristic of the majority of the questionnaire respondents are male with the age of 18 years old, who typically own smartphone with Android operating system. The respondents with mean score 4.90 out of 5 frequent use app in social category such as 'Facebook', 'Twitter', 'Instagram'.

This study sought to explore students' perceptions towards Aero Intel mobile app. Based on the results, the majority of students have positive perceptions on the use of Aero Intel app. The results of this study indicate that the students may access to Aero Intel app more easily and useful because the students' accessibility to learn anywhere and anytime. The results also indicated that Aero Intel app will save time to get information regarding aircraft airframe.

\section{REFERENCES}

[1] Pilomia, J. 2011. User experience in mobile application development: Developer and end-user perceptions. M.Sc. thesis, University of Tampere.

[2] Herbet, A. 2011. Smart phones and their impact on the workplace, education and social engagement. Retrieved from http://www.slideshare.net/Devon26/smartphonesand-their-impact-on-the-workplace-education-andsocial-engagment.

[3] Mangukiya, P. 2012. How mobile apps are changing classrooms and education. Huffington Post.

[4] Lisekelo, K., Juma, M. R. 2015. A review on the impact of smartphones on academic performance of students in higher learning institutions in Tanzania; A case of Ruaha Catolic University (Rucu), Iringa. 
Journal of Multidisciplinary Engineering Science and Technology, 2, 673-677.

[5] Zamri, M., Nur Aishah, M.N. 2011. Teachers ' perception about the use of multimedia application in teaching English literature component. GEMA Online Journal of Language Studies, 11 (3): 163177.
[6] Federal Aviation Administration. 2012. Aviation maintenance technician Handbook-Airframe, Volume 1. United States Department of Transportation, Oklahoma.

[7] Federal Aviation Administration. 2008. Joint aircraft system/component code table and definitions. Mike Monroney Aeronautical Center, Oklahoma. 